\title{
Should all Abscesses be Drained? A Viral Infection of the Hands
}

\author{
*Vahit Onur Gul, MD \\ Edremit Military Hospital General Surgery Dept. \\ 10300 Edremit/Balikesir Turkey \\ vonurgul@hotmail.com \\ Serhat Ozer, MD \\ Konya Military Hospital General Surgery Dept. \\ 42040 Konya Turkey \\ serhatozer78@yahoo.com
}

Sebahattin Destek, MD

Via Hospital General Surgery Dept. 34947

Tuzla/Istanbul Turkey

sebahattindestek@yahoo.com

Serkan Ahioglu, MD

Yesim Erbil, Prof.

Edremit Military Hospital General Surgery Dept. 10300 Edremit/Balikesir Turkey

drserkanahi@yahoo.com

Istanbul University General Surgery Dept. Istanbul Turkey

yerbil2003@yahoo.com

\begin{abstract}
Orf is a zoonotic disease, which is caused by the parapox virus limiting itself and this disease can be transmitted by touching animals or infected flesh. This is usually seen on butchers and vets. The disease can be healed spontaneously and its treatment is symptomatic. The patients, going to hospitals complaining that there are abscesses on their hands, may encounter with wrong diagnosis and unnecessary surgical attempts. We are aimed at increasing the awareness of doctors to decide how to naje the treatment plan by taking the Orf on patients into consideration. On this study, we examined the Orf diagnosis, monitored on a 21 -years old patient.
\end{abstract}

Keywords: Orf, symptomatic treatment, zoonoz, parapox virus.

\section{INTRODUCTION}

Orf is a dermotologic disease known as contagious dermatitis or ecthyma. The disease is caused by the Orf virus and this virus is from the parapoxvirus family having double spiral (1). It's also a zoonoses that can be transmitted to human by touching animals like sheep and goat directly or infected flesh and contaminated waste.

The risky group consists of farmers, butchers, vets and those distributing flesh. It has not been reported that it is transmitted from person to person (2). The virus is seen as rare in the world and it is rarely reported to be seen as it limits itself (3). The Orf, seen on human, is a solitary nodule which is 2-1 cm caliber. The lesion is generally seen on hands, wrists and forearms, but rarely on face. Clinically, in a week after the contact, there happens a red maculopapuler lesion. This lesion is transformed into a nodule, on which there is a bulla. On this phase, lesion causes edema and it is so sensitive, bleeding very easily. In a week, there happens tiny pappilomes and these form thick crusts covering the surface. Then, it heals itself spontaneously in 6-8 weeks by giving out a superficial scar (1).

In recent years, there have been different alternative antiviral agents such as idoxuridine (3), cidofovir (4) and imiqumod (5) and shave excision cryotherapy (6) to heal the disease caused by Orf. We've found it suitable to present our phenomenon to examine Orf, which can be healed symptomatically without giving out any scars.

\section{CASE}

A 21 years-old man came to our clinic, complaining about lump and spasm on the first $, 2^{\text {nd }}, 4^{\text {th }}$ fingers on his right hand and on surface of the same hand. He said he is a butcher and told us that he was in contact with zoic products. After the examination, we realized that there was hemorrhagic bulla which was erythematus and had edema on his right hand- first finger (0.5), right hand forth finger (0.5), right hand third finger (0.5) and the nodules were so sensitive. On the right axilla, a lymph $(1 \mathrm{~cm})$ nod was detected. 
On the right hand of the patient, there were widespread edema, hiperema and heat increase. On the liquid extracted from the lesion, it was realized that there were 2 neutrophil, on every tract. There was no reproduction culture. The diagnosis result was the Orf on the patient by taking clinic examination into consideration. In addition, the patient was given $1000 \mathrm{mg}$ oral amoxicilin clavulanate treatment, thinking there could be secondary infection. Having the patient used antibiotic for 10 days, it was detected the pain and edema were disappearing slowly. It was also monitored that the lesion disappeared spontaneously without any more intervention.

\section{DISCUSSION}

The reason why the Orf disease is ignored much is because the disease limits itself (3). For some time, it may lead to systemic fever and weakness. Especially, it is usual to see recurrence on risky people. On atopic dermatitis, transparent receivers and insufficient immune conditions, lesions may form exophytic masses, repeat themselves or become persistent (7). The disease is generally seen in spring and summer months. Any sex separation hasn't been reported yet. All patients are males. Cause they are more in contact with animals (8). The disease is generally seen on hands and faces, rarely on the other parts of the body (3). The lesions emerge as sole or a few on the hands which are not dominant (1).

But in our study, we realized that there was more than a single lesion on the dominant hand of the patient. In addition, Orf can be seen together with Stevens Johnson syndrome, generalized mucocutaneous eruption, edema on eyelid or big, stubborn and ongoing lesions on patients whose immune systems are too weak. On immune compromised patients, there could be bigger and fungal lesions (8). On the other hand of our patient, we detected a cellulite with a widespread hyperemia and a sensitive lymphadenopathy $(1 \mathrm{~cm})$ on his armpit. After the oral amoksasilin clawlanate treatment, the lesions were healing spontaneously. It is easier to decide the diagnosis if we learn the patient is in contact with any animal. The lesions of our patient began with the contact with blood of a sheep in a week and the diagnosis was decided by taking his story and clinic studies into consideration. If someone wants to verify it, it can be done with the help of electron microscope, PCR or histopathological study. But histopathological study findings may change from patient to patient. These include pyknotic- epidemic cells, paleness on epidermis, eosinophilic inclusion, histiocytes, macrophages and lymphocyte infiltration (1). In the distinctive findings of the disease, there may be anthrax, pyoderma,gangrenosum, herpetic felon, felon, milker's nodule malignant melanoma, staphylococcal dermatologic infections, atypical mycobacterial infections, tularemia and nokardiasis (9). Specific antiviral treatment against the disease is not possible. On the same study, it was found that cidafovir, idoxuridine and imiquimod tropical cream may give patients some benefits. In Orf treatment, cryothrerapy, surgical excision and iterfenon were also used (3). For the treatment of big lesions or on patients having weak immune systems, alfa interferon injection into lesions or cream with cidofovir can be used (10). In addition, it slowly loses its population these days although 'shave' excision is an usual way to heal Orf disease and it is preferred by most doctors (6). In Ireland, there is an attenuated vaccine and it is used for the Orf treatments (8). It is also important to give importance to your hand hygiene and learn about the ways to protect yourself from this disease.

\section{Conclusion}

Today, there are not so many reports about this disease, but we may encounter with wrong treatment methods to heal the disease. Mostly, surgical interventions rather than symptomatic are applied to heal patients complaining about scars and abscesses on their hands. Although this disease may disappear without applying to any treatment, there are lots of unnecessary surgical intervention and healing methods. With this study, we are aimed at increasing the awareness of doctors about arranging the true treatment plan by not ignoring patients' stories with animals.

\section{COMPETING INTERESTS AND FUNDING STATEMENT}

The authors declare that they have no competing interests and any sources of funding for our publication. 
Should all Abscesses be Drained? A Viral Infection of the Hands

Table. Characteristics Orf Virus Infections in Animals And Humans

\begin{tabular}{|l|l|l|}
\hline & Animals & Humans \\
\hline Incubation period & $2-3$ days & $3-7$ days \\
\hline Mode of transmission & Direct contact & Direct contact, \\
\hline Clinical signs & Papules, pustules, vesicles & Papules that progress to pustules \\
\hline Treatment & Supportive & Supportive \\
\hline Course of disease & Self-limiting & Self-limiting \\
\hline Complications & $\begin{array}{l}\text { Anorexia, starvation, lameness, } \\
\text { secondary bacterial infections }\end{array}$ & $\begin{array}{l}\text { Secondary bacterial infections, } \\
\text { bullous pemphygoid, erythema } \\
\text { multiforme, toxic erythema }\end{array}$ \\
\hline Vaccine & Yes & No \\
\hline $\begin{array}{l}\text { Important differential } \\
\text { diagnoses }\end{array}$ & Foot and mouth disease & $\begin{array}{l}\text { Cutaneous anthrax, tularemia, } \\
\text { primary inoculation tuberculosis, } \\
\text { eyrsipeloid, sporotrichosis }\end{array}$ \\
\hline
\end{tabular}
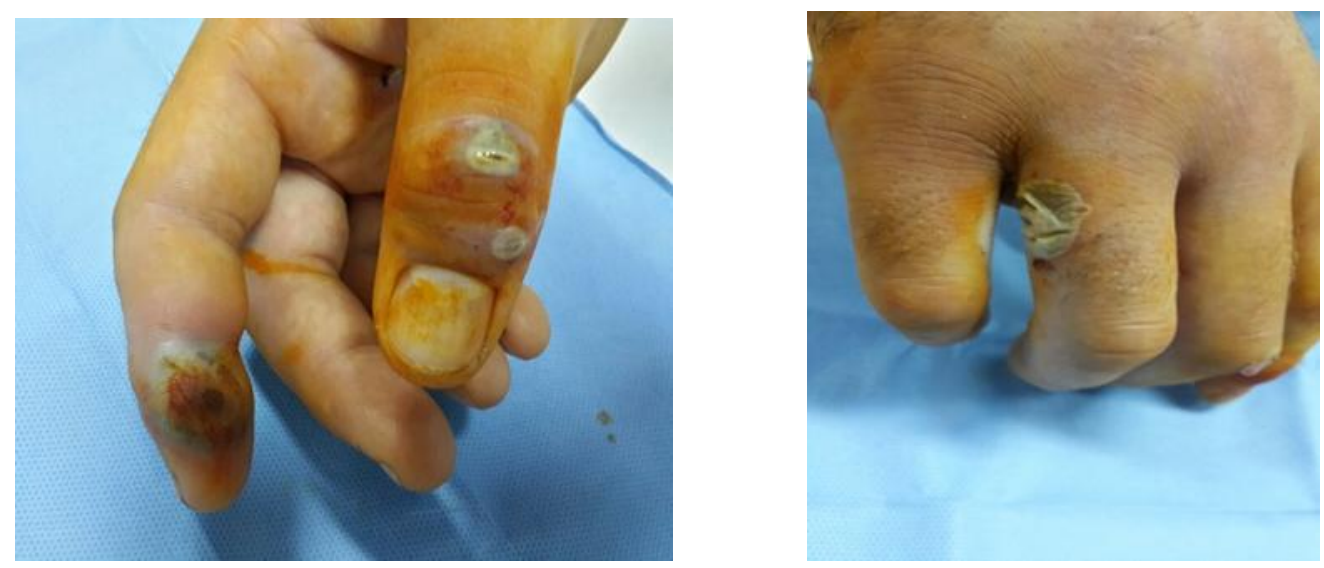

Figure1. Lesions at First Presentation
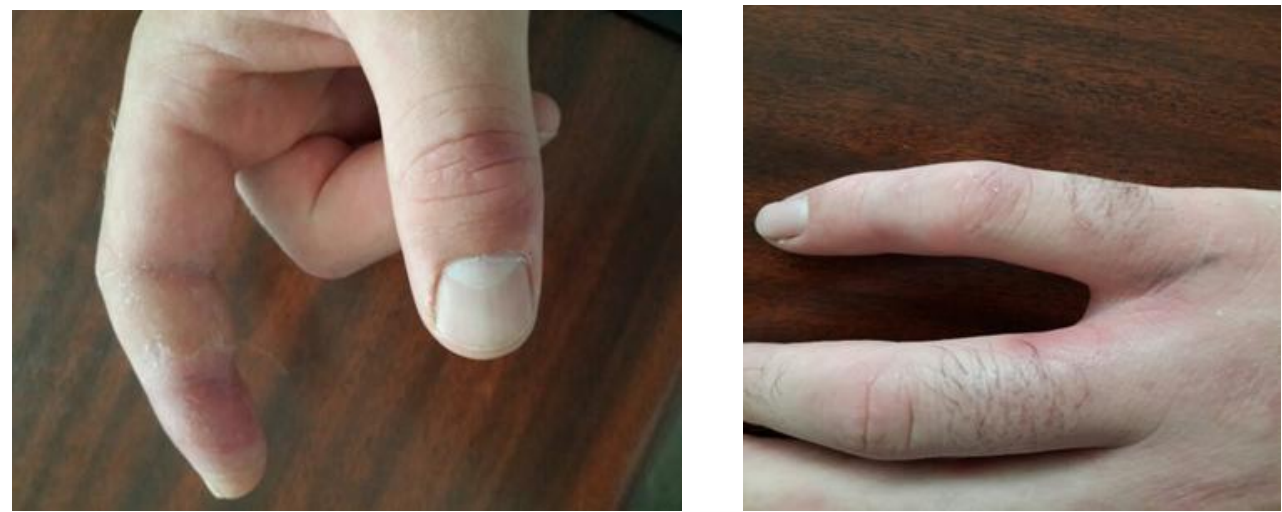

Figure2. Lesions after Four Weeks

\section{REFERENCES}

[1] Uzel M, Sasmaz S, Bakaris S, et al. A viral infection of the hand commonly seen after the feast of sacrifice: human orf (orf of the hand). Epidemiol Infect 2005;133:653-657.

[2] Schmidt E, Weissbrich B, Brocker EB, Fleischer K, Goebeler M,Stich A. Orf followed by erythema multiforme. J Eur Acad Dermatol Venereol 2006; 20: 612-613.

[3] Gurel MS, Ozardali I, Bitiren M, San I, Zeren H. Giant orf on the nose. Eur J Dermatol 2002; 12:183-185.

[4] Damon IK. Other poxviruses that infect humans: Parapoxviruses, Molluscum contagiosum, and Yatapoxviruses. In:Mandell GL, Bennett JE, Dolin R, eds. Mandell, Douglas, and Bennett's Principles and Practice of Infectious Diseases,7th edn. Philadelphia: Churchill Livingstone Elsevier,2010:1933-1936.

[5] Erbagci Z, Erbagci I, Almila Tuncel A. Rapid improvement of human orf (ecthyma contagiosum) with topical imiquimod cream: report of four complicated cases. J Dermatolog Treat 2005; 16: 353-356. 
[6] Deqraeve C, De Coninck A, Senneseael J,Roseeuw D.Recurrent contagious ecthyma (Orf) in an immunocompromised host succesfully treated with cryotherapy. Dermatology 1999;198:162-63

[7] Ballanger F, Barbarot S, Mollat C, Bossard C, Cassagnau E, Renac F, Stalder JF. Two giant orf lesions in a heart/lung transplant patient.Eur J Dermatol 2006; 16: 284-286.

[8] Nadeem M, Curran P, Cooke R, Ryan CA, Connolly K. Orf:contagious pustular dermatitis. Ir Med J 2010;103:152-153.

[9] Frandsen J, Enslow M, Bowden AR. Orf parapoxvirus infection from a cat scratch. Dermatology Online Journal 2011;17(4):9

[10] Geerinck K, Lukito G, Snoeck R et al. A case of human orf in a immuncompromised patient treated successfully with Cidofovir cream. J Med Virol 2001;64:543-549 